\title{
EDUCATING PRODUCT BASED START-UPS: FOCUSING ON THE BUSINESS OR THE PRODUCT?
}

\author{
Mads Prahl JØRGENSEN, Rasmus Hald VINDELøV and Linda Nhu LAURSEN \\ Aalborg University, Denmark
}

\begin{abstract}
A product-based start-up will need to both develop their product as well as their business model to succeed. However, as a start-up typically only has limited resources, they often tend to focus on either the business or product side. While it is commonly acknowledged that both the business and the product need to be for a product-based start-up to succeed, we however find many educational programmes drive start-ups to refocus on the business aspects.

In this article we study the different challenges that occur when starting a start-up focus on the business or product respectively. We map the process and the challenges of product and business-based start-ups, to understand common obstacles, tendencies and solution strategies. Through case studies of 7 start-ups that went through business focused start-up programmes we find, how business focused start-up programmes, help and forces product focused firms, to develop and take business aspects into account. Opposite we also identify, while developing, the product is central for a product-based start-up, we however find these aspects do not receive the same attention in educational programmes for start-ups, and how business based firms are left on their own. We suggest educational programmes for start-ups to take the focus of the start-up in mind, so they may assist with complementary knowledge on either business or product aspects.
\end{abstract}

Keywords: Start-up, product based, business based, process, focus

\section{INTRODUCTION}

Running a start-up often means trying to run a business with very limited resources, when it comes to money, manpower and time. Both the product and the business need to be developed, but since the resources are scarce, start-ups often for periods of time end up focus on either or. However simply focusing on one side of your start-up could lead to neglect and possibly failure because you simply have not developed certain aspects of your business. Therefore, moving between the two focuses is considered important to the survival of the business. It is not exactly clear when to shift between the two focuses, and what the consequences are for staying to long in one focus or switching to often.

Today many entrepreneurial programmes help start-ups to figure out their business model, driving them through a business development process that supports them in and help them focus on 'how to develop the business aspects'. We propose product-based start-ups, beyond developing and maturing the business model, however, also need to develop and mature their product. While developing, the product is central for a product-based start-up, we however find these aspects do not receive the same attention in educational programmes for start-ups. In fact, to our knowledge there are no entrepreneurial programmes, which help start-ups in figuring out 'the product design, aspects', e.g. driving start-ups through product development process.

The purpose of this article is to determine the focus different start-ups have, and how this influences their process. In this paper, we examine 7 cases of product-based start-ups, to understand whether and how the product or the business aspects, in terms of focus, influence the process of product-based startup. All the product-based start-ups are parts of an entrepreneurial educational programmes, which helped them through a business development process. In this study, we examine how the business focus in the educational programmes, influence the start-up process. In the following we will first build on past literature to understand important differences in business and product-based focus, and to define important parameters to understand the start-up processes. Next, we will analyse 7 start-up cases. 


\section{THE DIFFERENCE BETWEEN A BUSINESS AND A PRODUCT FOCUS}

\subsection{Business focus}

When a start-up is focused on the business aspect, they work with the construction of a company. This means a large focus on creating contacts, gathering competencies, using what is at hand to find opportunities to develop their business model. For clarification this article defines a business focus, as concerning the values of the business, market knowledge, competing businesses, funding, team competence and empathizing with stakeholders and customers. This means that the focus of a start-up should be to focus on finding customers and ultimately selling the product. The goal should be, as Steve Blank puts it; "A start-up is a temporary organization searching for a scalable and repeatable business model" [1].

That said, it does not mean that the start-up should not be open to changing or adapting to a given situation. It is a constant changing and adapting to changing opportunities, made from either new contacts, customers or suppliers. This what is referred to as a pivot "In lean start-up lingo, "pivoting" refers to a major change in a company's direction based on user feedback. "[2; p1]. It should be noted however, that other factors also play into this, such as brand awareness, reputation and opportunity costs [3]. With a business focus, pivoting would involve changing the direction of the company and its employees. The main goal of pivoting is to establish something called a product market fit, which is deemed essential to the survival of a company. These could be elements such as market potential, financing and business strategy among others [4]. This means, that in the mind of a business focused company; "That metrics designed to evaluate the impact of MVPs should measure the real business impact and not simply produce feel-good results through "vanity metrics"." [4, p. 25] I.e. The success of a product should be measured in units sold, rather positive user feedback.

\subsection{Product focus}

Product focused mindset is much more focused on the product itself. As a rule, the product is minded solving a specific problem or filling a specific need. For clarification, the product focus will be considered as a focus on product values, product development, competing solutions, user values, ideation, production optimization and testing. For the product focused start-up the product will take centre stage with the belief that the product itself provides means to contribute towards its own success, as Peter Bloch puts it: "The physical form or design of a product is an unquestioned determinant of its marketplace success. A good design attracts consumers to a product, communicates to them, and adds value to the product by increasing the quality of the usage experiences associated [5, p. 16]. This means there is a focus on iteration, development and testing of the product, so that the value it creates, user experience and the impressions of the user are as good as they can be [4]. Also, well designed product needs to align to many different aspects, and these aspects can be affected by factors that are constantly changing. The product focus doesn't necessarily see "customers", instead the focus is on the "users". To summarize, it should be important to highlight that neither having a focus on business or product is superior to the other, however it is widely accepted that both aspects needs to be considered: the "...optimum innovation occurs and is based on understanding the needs of the end-customer and creating products or services that fulfil their needs and desires and that generate sufficient value for the company." $[4, \mathrm{p} .6]$.

Table 1. "Business focus versus product focus [4]

\begin{tabular}{lll}
\hline & Business focus & Product Focus \\
\hline Development & Business development BD & Product development PD \\
Validation & Market Validation MV & Proof of Concept PC \\
Target groups & Early adopters EA & User testing UT \\
Insights & Market opportunity MO & User need UN \\
Value creating & Marketing M & Production P \\
Networking & Seeking Co-workers SP & Seeking Suppliers SS \\
\hline
\end{tabular}




\section{METHODOLOGY}

To research start-ups focus on the environment that influences them, we tend to case studies. That makes it possible to research complex phenomenon in the real complexities of reality. Our objective is "confront theory with the empirical world". [6, p. 555]. For the selection of the companies that was used as cases, an information centric selection strategy was applied. The intention behind the strategy was to gather information from start-ups with either a design focus or business focus. While it may not represent the broader population, the start-up was chosen on the background of how much relevant information they could provide. The type of companies are start-ups from university environments. Whether the start-ups have a business or product focus is determined by their education/training. Thus, we assume product designers, tend to naturally have a product focus while business students are inclined to focus on the business aspects.

We did a multiple case study as: "multiple sources may contribute to revealing aspects unknown to the researcher, i.e., to discover new dimensions of the research problem" [6, p. 556]

For our case studies we deployed two data collections strategies. First, semi-structured interviews were used. The reasoning for the use of this method that the problems of start-ups often are unique compared to one another, thus it was important to still leave room for following new relevant directions in the conversation. The intention of the interviews were to create a structured timeline that was able to illustrate the shift between the different focuses, as well as how long they stayed in the respective focuses and what difficulties they encountered and at what time they encountered them. The interviews were conducted with the same start-ups, twice, with 3 months of spacing, to observe changes in focus or to observe if they had overcome previous difficulties or have gotten stuck. Second, secondary data sources such as social media (Facebook and Instagram) were used to supplement the interviews. To confirm the dates and stories of what the respective companies work on at a given point in time. These timelines and datasets will be compared in the analysis chapter, to determine patterns and consequences of focus.

\subsubsection{The educational programme}

The 'AAU incubator programme' is a 6-9-month programme, made available for all students at Aalborg University. The main purpose of the AAU Start Up Programme is to provide the students with knowledge required to develop a start-up. The students enter the programme with a start-up idea. The purpose of the programme is described as to: "spend time talking to customers and partners, and assess your technology; find team members; define the business model; and have a pretty good sense of what you need to make a business out of your idea. Then you can look for financing and launch." [7, p. 4].

The start-ups in the programme go through the following topics, that are either taught as traditional courses, workshops, exercises, pitches or discussed in networks: 1) customer validation, 2) technology validation, 3) google design sprint, 4) Start-up tool box, 5) Competition and Benchmarking, 6) Team, 7) Pitch, 8) Funding, 9) Registering a company, 10) Mentor [7]. There are 2 stages of the programme. During the first 3 months, the start-ups should be able to describe target customer and price point. In the following months, they should be able to describe, what the business setup should look like. At the end of the programme, the students' performance is evaluated by a business panel, that asses a business pitch that is either approved/not approved [7].

\section{ANALYSIS}

From the data that has been gathered, certain characteristics have been observed in the different companies. As stated by Darian Unger earlier in the article, most start-ups are very different in their process, so the groups have been split up according to their focus, mapping their development process. This is to find issues, challenges, dilemmas and solutions common between the different start-ups. We discuss shared findings between based start-ups with either shared focus; as well as comparing different process with each other, to understand how shared challenges, may lead to different consequences and solution strategies. 
Table 2. Coding scheme

\begin{tabular}{|l|l|l|l|l|l|l|}
\hline Code: & Meaning & & & \\
\hline B & Business Based start-up & CS & Case study & IV & Innovative growth \\
\hline P & Product Based start-up & MV & Market validation & ID & Idea \\
\hline VN & Validation of need & IS & Insight & P & production \\
\hline & & & & N & \\
UT & User test & SF & soft founding & W & Network \\
\hline CD & Concept development & HF & Hard founding & EA & early adopter \\
\hline BC & Business Case & SP & start-up programme & V & venture \\
\hline PD & Product development & t & Team building & & \\
\hline
\end{tabular}

Table 3. Coding of development. The period is divided into segments of one month

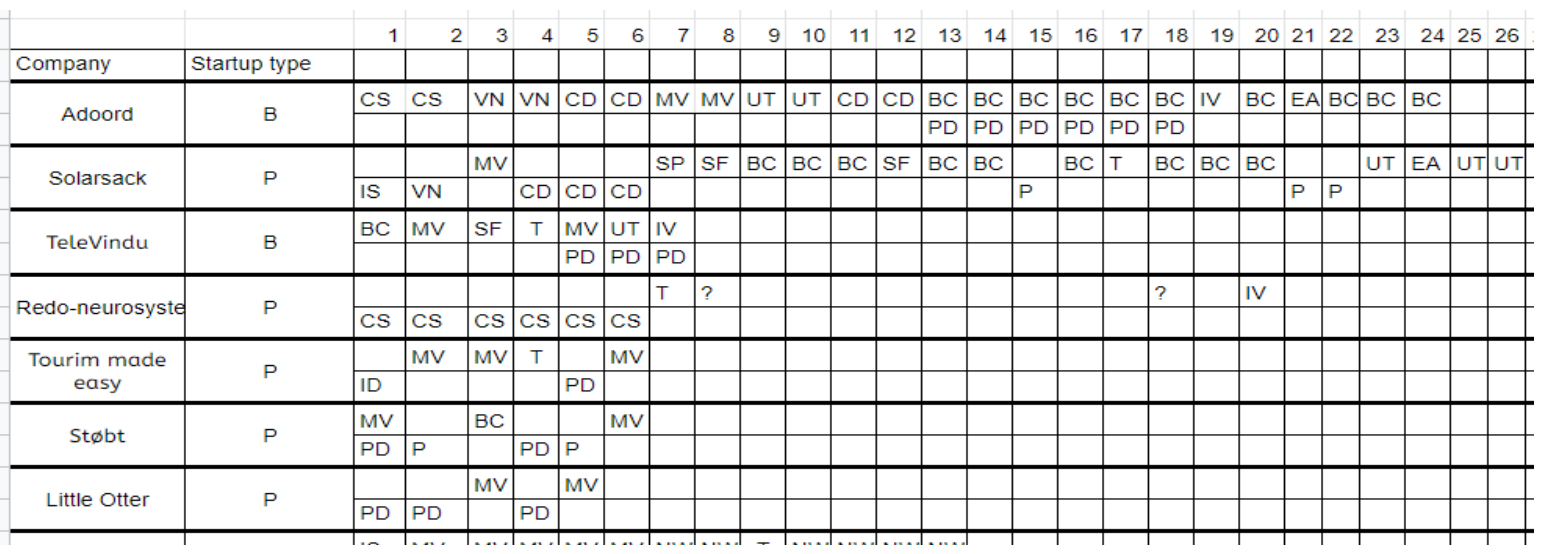

\subsection{Business focused}

Skovmose: Company founder wished to start a business surrounding the idea of a new on-flight cart for airlines, that had better ergonomics and user experience. Skovmose focused on the business, and when the actual product had to be designed, it resulted in a pivot that had

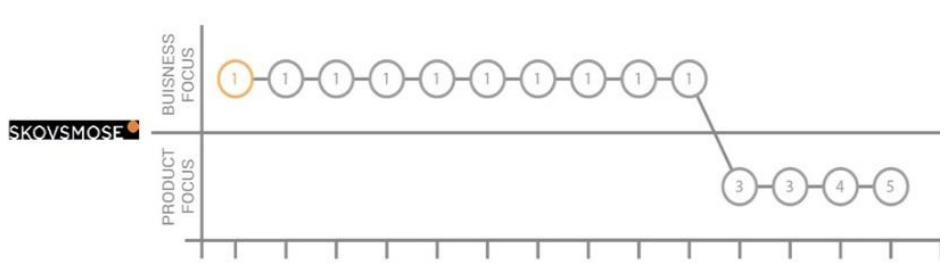
large consequences the business.

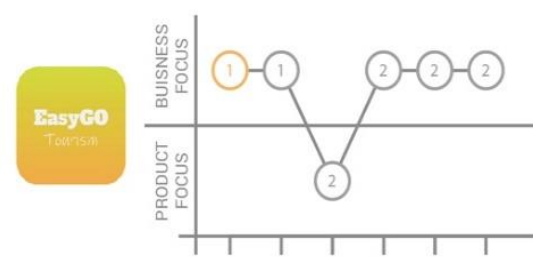

EasyGO Tourism: wanted to create an application that provides tourists with the information and possibilities they need, whenever they visit a given location. EasyGO had the approach of validating a potential value proposition through interviews of potential customers, networking with potential employees and pitching the idea to potential partners. Currently, EasyGO is looking for programmers and partners to work on the product development.

Televindu: Televindu wanted to make a company around providing a Slow-TV service for elderly homes, increasing comfort for the elderly living there. Televindu, that from the start was business focused, they did not have the skills required to create a minimum viable product themselves, so they hired new personnel to overcome their challenges.

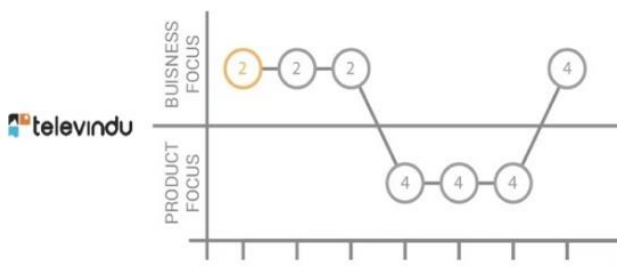




\subsection{Product focused}

SolarSack: SolarSack is a start-up based on a master's project in industrial design and therefore had a long period of product focus, before becoming a start-up. Solarsack had the same issue for a very long time, having a hard time crossing over from the product focus to the business focus. The entrepreneurial programmes which emphasized a focus on the business aspects, made the founder aware of his lacking business abilities/focus; and after an extended period of searching for partners with relevant business abilities, the company expanded.

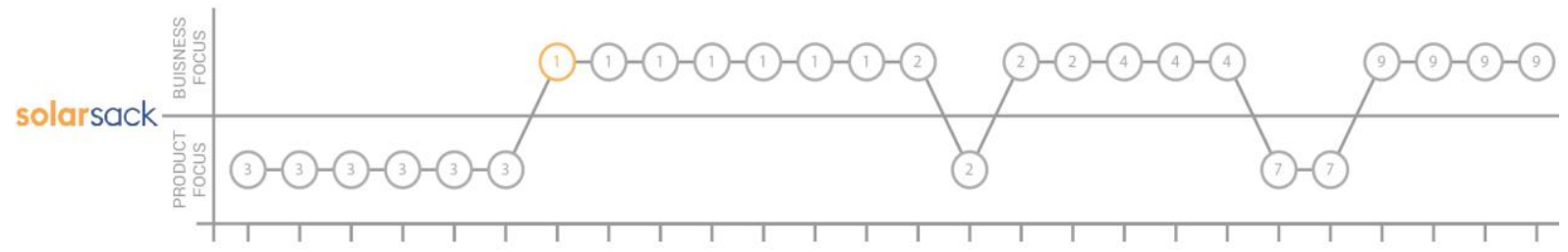

Redo-Neurosystems: Redo is based on a product capable of visualising phantom pain for patients with missing limbs. Redo-Neurosystems had a long period of time focused on the inner workings of the product, until they entered the business incubator programme and it was decided that there had to a business established around it. They managed to make this transition smoothly, since they were encouraged by circumstances and the previous work did not suffer as a result.
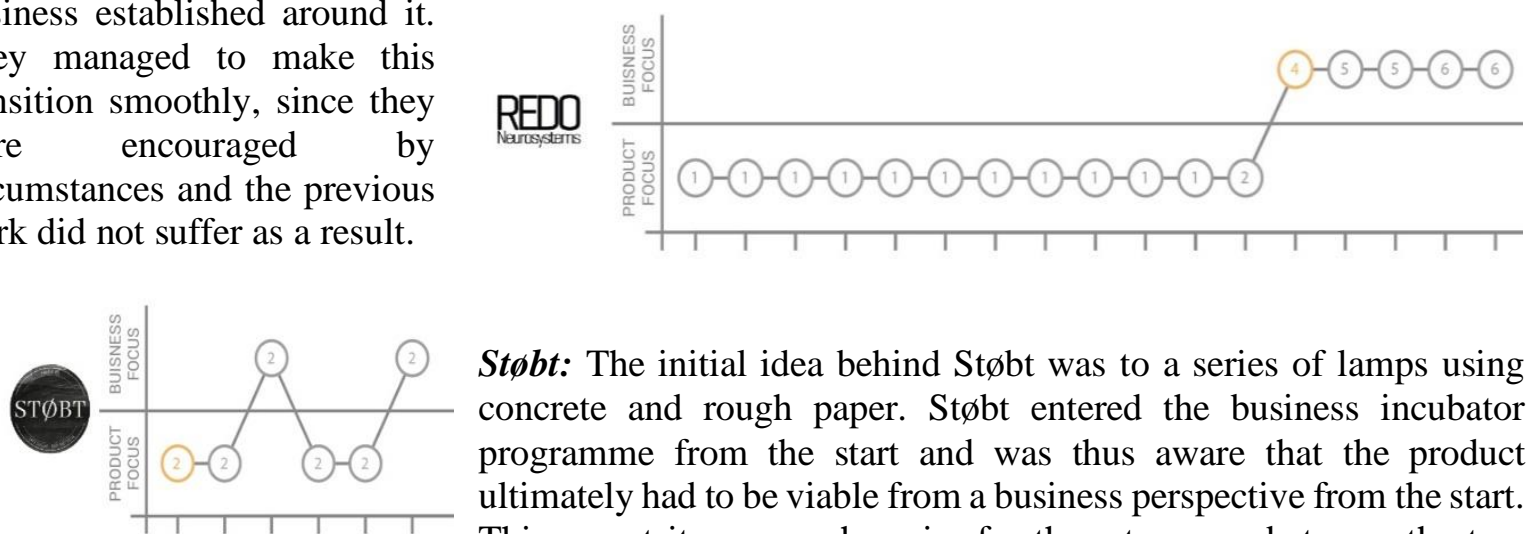

Støbt: The initial idea behind Støbt was to a series of lamps using concrete and rough paper. Støbt entered the business incubator programme from the start and was thus aware that the product ultimately had to be viable from a business perspective from the start. This meant it was much easier for them to move between the two focuses, without bringing in more external knowledge.

Little Otter: Little Otter wanted to build a speaker that broke the aesthetic mould. They are currently completing a business incubator programme that helps them develop their business around the speaker, as well as trying to find suppliers and manufacturers of their speaker. Little Otter tended to focus on the product, with prototyping being a big concern. However, they have for short periods done business focused activities, to get validation for the product.

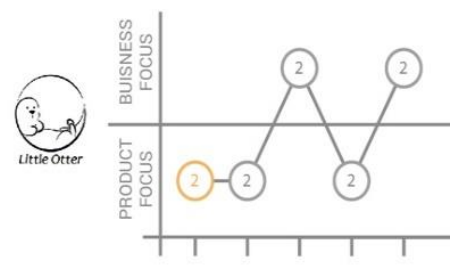

\section{DISCUSSION}

In the following we will discuss some of the challenges and consequences that focus during the process had on the companies in question. This section we discuss some of these dilemmas.

Firstly, there seems to be helpful educational programmes directed towards the business side of a startup. Støbt, Little Otter and Redo-Neurosystems are three product focused start-up that has benefited greatly from these programmes, as they already were product focused. It can be argued that these programmes definitely have helped the start-ups with changing focus, and if they did not have these programmes, they would likely have remained in a product focus, at the detriment to the product. Moreover, we find indications of the earlier these product focused start-ups enter a business incubator programme, the earlier they shift between the two complementary focus areas. This provides the main benefit, that the business and product aspects are earlier and more naturally integrated. The cases that remained agile and shifted focus often, seemed to be able to prevent running towards a dead end, or were able to make quick pivots, since both the business focus and product focus was swapped between often, and did not stagnate. It is the recommendation from the article that this would be a mentality that should be adopted by most start-ups, to avoid unnecessary setbacks.

Secondly, However, for those companies, who stayed for an extended period in one focus area, several of these companies experienced problems in crossing over into the other focus area. The business 
focused firms turned out to have difficulty shifting focus without bringing new people into the company; or alternatively hiring externals to do the central product development task. Whereas some of the design focused firms such as Støbt and Little Otter managed to consider the business aspects due to guidance during the business incubator programme. It should be noted that the interviews indicated that sometimes the attitude towards certain activities was that they were "in the way" or prevent them from focusing on the activities that they enjoy doing. We find companies that focus on only the business or product aspects for an extended period, i.e. have a sequential process, need to be helped to change focus. Solarsack (product focused) and Skovmose (business focused) two cases of companies with a single focus for a longer period. Solar sack entered the business incubator programme quite late. Even though the educational programme helped Solarsack pivot and change focus, they did not do it before they were forced to, by getting into a start-up programme. Both these companies managed to transfer into another focus, and they did so by a common solution: They brought more people into the Start-up that matched the expertise they needed. Should a start-up want to prevent this, it is recommended that the start-up either get the knowledge, for example through educational programmes, or the people they need to shift focus, before proceeding much further with previous work.

\section{CONCLUSIONS}

Even though the study indicated very different motivations for starting. Start-ups that start with a natural business or product focus, tend to revert to their focus automatically after a short period of time. Hence, start-ups ups with a product focus tended to change their product, instead of changing the business model, as observed with Little Otter. This could be caused by the fact that most people start with a focus that are already familiar to them, either through education or work experience. Start-ups with a large expertise in one focus could tend to pivot with elements familiar to them, instead of making the changes that are really needed.

Second, we find all the product focused companies, that entered the business incubator programmes early on, are due to the programme helped to switch into other focuses and potentially pivot into other or better products/market fits. This might be because they were made aware that even though their motivation in the company lay in a specific area, exploring activities within a different focus could be essential to progress and to prevent the start-up from stalling. Thus, parallel focus enhanced a simultaneous maturation of both the product and the business.

In contrast, there seems to be a lack of educational support when it comes to getting business focused start-ups to move into the product focus. They tend to stay in the business focus, and require other people to drag them over, or convince them to shift focus to the product side. A recommendation from this article, was that these start-up programmes should also include product focused advice, as to help these companies to move out of a business focus much earlier. For educators attending this conference, an investigation, suggestion and discussion of how such product focused start-up programme would look like is an avenue for further research.

\section{REFERENCES}

[1] Blank, Steve. (2010) What's A Start-up? First Principles: https://steveblank.com/2010/01/25/whats-a-startup-first-principles/.

[2] Nobel, Carmen. (2011). Teaching “The Lean Start-up” Strategy, p. 1.

[3] Zott, Christopher. (2008). The Fit Between Product Market Strategy and Business Model: Implications for Firm Performance, p. 25.

[4] Dennehy, Denis. (2016). Product Market Fit Frameworks for Lean Product Development, p. 6.

[5] Moogk, Dobrila. (2012). Minimum Viable Product and the Importance of Experimentation, p. 25.

[6] Bloch, Peter. (1995). Seeking the Ideal Form: Product Design and Consumer Response, p. 16.

[7] Dubois, Anna. (2002) Systematic combining: An abductive approach to case research, p. 555. "multiple sources may contribute to revealing aspects unknown to the researcher, i.e., to discover new dimensions of the research problem".

[8] Inkubator, AAU. https://www.sea.aau.dk/digitalAssets/387/387247_upstart_good_advice.docx. 